\title{
ARE WE ABLE TO GIVE FIRST RESPONDERS THE TOOLS TO CONTROL BLEEDING?
}

\author{
Kobi Ludwin
}

Polish Society of Disaster Medicine, Poland

Sir,

Following the recent terrorist attacks on civilian populations around the world, especially in Europe, the need for expanding the distribution of haemorrhage control devices to the masses, along with the education and know-how of how to use them, is becoming more and more evident. Uncontrolled haemorrhage, where the systolic blood pressure drops under 50 , results in an average time of death of approximately 18 minutes [1]. One must add to this the fact that up to $80 \%$ of civilian trauma fatalities within the United States are from uncontrolled extremity haemorrhage [2] and that many mass casualty patients are delivered to a professional care centre by members of the general public, not by ambulance. It is therefore apparent that giving first responders, and even the general population access to haemorrhage control devices such as tourniquets, emergency bandages and haemostats, will save lives.

On April $2^{\text {nd }}, 2013$, a joint committee with members from several law enforcement and emergency response agencies gathered in the United States to determine a national policy in order to enhance survivability from intentional mass casualty shooter events. This was later referred to as the Hartford consensus. Even though law enforcement officers are usually the first to arrive on the scene, on many occasions they lack the medical training and medical equipment needed to deal with mass casualty incidents, mass shootouts and to control severe hemorrhagic wounds. This understanding initiated the focus of the consensus - to create implementation strategies for effective haemorrhage control with an overreaching principle, namely that no one should die from uncontrolled bleeding [3]. This has led to an overall review of police officer training in the United States, adding haemorrhage control to core law enforcement tactics. By 2014, more than 36,000 police officers had received haemorrhage control training and bleeding control kits: namely, kits which included the basics for haemorrhage control - a tourniquet, an emergency bandage and a haemostat [4].

On October $6^{\text {th }}, 2015$, the evolution of education and access to haemorrhage control went up a grade following the stop the bleed coalition, initiated by the White House in coalition with the American Red Cross, the American Heart association, the American College of Surgeons, the Hartford consensus and others. The idea behind this initiative is to empower bystanders to act as first responders in such events, with the full aim of providing public access to bleeding control tools already proven in the field by first responders and the military.

Even though history has brought to Europe's doorstep events in which civilians are targeted by different mass casualty incidents, it appears that re-

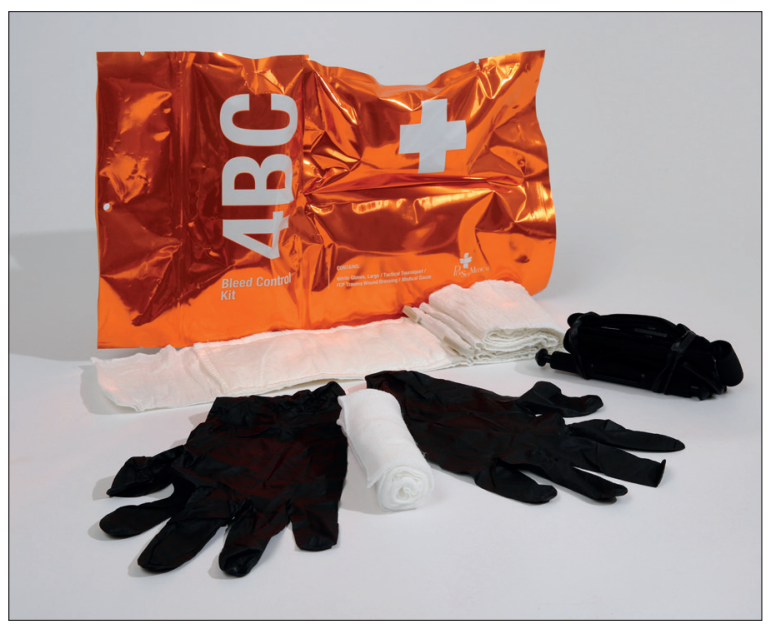

FIGURE 1. Example set for control of bleeding 
cent terror attacks across the continent have caught Europe by surprise regarding the tools and education required for haemorrhage control by first responders and members of the general public in the field (Figure 1). Already, in 2010, it was established that: "Where the prevalence of severe trauma is high, trauma first responders should be an integral element of the trauma system" [5]. However, it appears that this has yet to be implemented in various countries in the European Union, as it has been in the United States.

\section{REFERENCES}

1. Howerd R, Ronald F, Roberts $P$, Leppaniemi A. A profile of combat injury. J Trauma Injury, Infection and Critical care, 2003; 54: S13-S19.

2. Sauaia A, Moore FA, Moore EE et al. Epidemiology of trauma deaths: a reassessment. J Trauma, 1995; 38: 185-193.

3. http://bulletin.facs.org/2013/09/hartford-consensus-ii.

4. http://bulletin.facs.org/2014/04/hartford-consensus-in-action-lawenforcement-gets-equipment-training-to-control-bleeding.

5. Murad MK, Husum H, Trained Lay First Responders Reduce Trauma Mortality: A Controlled Study of Rural Trauma in Iraq. Prehospital and Disaster Medicine, 2010; 25(6): 533-539. 